\title{
Development of a Multi Degree-of-Freedom Vibration Exciter for Laboratory Applications
}

\author{
Oyedeji O.I., Apalowo R.K.*, Dahunsi O.A. \\ Federal University of Technology Akure, P.M.B. 704 Akure, Nigeria \\ E-mail: rkapalowo@futa.edu.ng*
}

Audu A.

Kaduna Polythecnic, P. M. B. 2021, Kaduna, Nigeria

Received: 28 July 2020; Accepted: 06 September 2020; Published: 08 December 2020

\begin{abstract}
Introduction of vibration to manufacturing operations such as casting and welding has proved to improve the physical and mechanical properties of manufactured parts. A vibration exciter is developed for the purpose of generating and inducing vibration, along different degrees of freedom, on objects placed on its surface. The equipment applies an eccentric mass drive system which gives the equipment an overall advantage in varying the vibration parameters. The acceleration of the vibratory motion of the equipment was measured using an accelerometer and oscilloscope set-up. The natural frequencies of the different vibration modes are also obtained from a developed mathematical model executed using the MATLAB Simulink software. The developed equipment successfully generated random sinusoidal vibrations of accelerations ranging from $-5 \mathrm{~m} / \mathrm{s}^{2}$ to $8 \mathrm{~m} / \mathrm{s}^{2}$ along the principal axes and angular accelerations ranging from $-40 \mathrm{rad} / \mathrm{s}$ to $40 \mathrm{rad} / \mathrm{s}$ about the pitch and roll axes. Natural frequencies of $\boldsymbol{f}_{\boldsymbol{x}}=3.78 \mathrm{~Hz}, \boldsymbol{f}_{\boldsymbol{\theta}}=7.94 \mathrm{~Hz}$ and $\boldsymbol{f}_{\boldsymbol{\varphi}}=9.89 \mathrm{~Hz}$ are obtained along the vertical, pitch and roll directions respectively. The presented results indicate that the developed machine successfully satisfied the proposed hypothesis of being able to measure vibrational characteristics along different degrees of freedom.
\end{abstract}

Index Terms: Vibration Exciter, Eccentric Mass, Mechanical Vibration, Design, Fabrication.

\section{Introduction}

Microstructural grain refinement has been reported as one of the most important factors of improving the quality of castings [Tamura et al., 2011, Dahunsi and Audu, 2006, Eshan et al, 2009]. Thus various methods have been proposed to refine and homogenize castings microstructures. Studies [Audu and Dahunsi, 2003, Omura et al., 2006, Zhao et al., 2010] have shown that the imposition of vibration is a proven approach among these methods. However, it necessary to determine the vibration characteristics responsible for the structural grain refinement. A vibration exciter, with the capacity of imposing vibration on an object placed on it, measuring and varying the vibration characteristics, is required for the task.

Application of vibration to casting manufacturing dated back to 1868 when the solidification of a melt was induced by vibration [Thoguluva et al., 2012]. Since then, developments have been made to establish the optimal vibration parameters for improving casting operations. According to [Abugh and Kuncy, 2013], introduction of high intensity ultrasonic vibration into melt controls the undesirable columnar structure and refines equiaxed grains. Microstructural uniformity of cast structure was achieved in [Zuo et al., 2016] by imposing electromagnetic vibration on Al-Zn-Mg-Cu alloy. The strength of aluminum A356 alloy was enhanced using ultrasonic vibration during the production of its castings [Jianbo et al., 2009]. Vibration has also been applied to other manufacturing processes such as burnishing of aluminum [Travieso et al., 2015], welding of stainless steel [Sakthivel and Sivakumar, 2014], laser powder deposition on alloy steel [Eshan et al, 2009] characterization of composite structure [Apalowo and Chronopoulos, 2018] and sieving of agricultural grains.

Several vibration exciters have been developed to generate and induce vibration for industrial and laboratory applications. They can be classified based on the type of mechanism used to produce the vibration excitation. Cam and follower mechanism [Pawar et al., 2016] produces a constant amplitude regardless of the applied load. However, the mechanism is comparatively difficult to set up. Meshing gear mechanism [Wowk, 1991] allows for an easy variation of shaft speed but it generates noise. Scotch yoke mechanism [Anekar et al., 2014] is easy to apply but only applicable for low speed device and wears easily. The rotating eccentric mass mechanism [Anekar et al., 2014, Gregory, 2011] is easy to fabricate, generates minimal wear and relatively easy to adjust. Though it does not allow for shaft speed variation, but the speed can be varied using DC motor with variable speed [Anekar et al., 2014]. Based on these comparative advantages, the eccentric mass mechanism is adopted in this work.

As reported in the literatures, focus has been placed on varying the eccentric force of an eccentric mass mechanism by 
changing the speed of the electric motor as it has the greatest influence on it [Sayuti et al., 2012]. The main contribution of this work therefore is to develop a vibration exciter which uses the rotating eccentric mass mechanism in which the eccentric force can be varied by varying the unbalanced mass and its eccentric distance. This is easier and cheaper to incorporate compared to using a variable speed DC motor. Also, developing an exciter which can generate vibration characteristics in different directions would be a great contribution to the literature. Therefore, the objective of this work is to propose a new varying-speed vibration exciter which can measure vibration characteristics along different degrees of freedom.

The remainder of this article is organized as follows: Section 2 presents the design development which involves the design calculations, drawing and description. Section 3 presents the fabrication of the designed device and its brief of operation. Results and analysis are presented in Section 4. Finally, Section 5 presents the concluding remarks of the work.

\section{Design Development}

Initially, a number of conceptual designs were proposed for the vibration exciter. Upon preliminary design calculations and analysis, the concepts were narrowed down to a viable solution. The final proposed design is a vibration exciter system which uses eccentric mass to generate vibration, and which has the capacity to attain seven degrees of freedom. The proposed design is presented in Fig. 1.

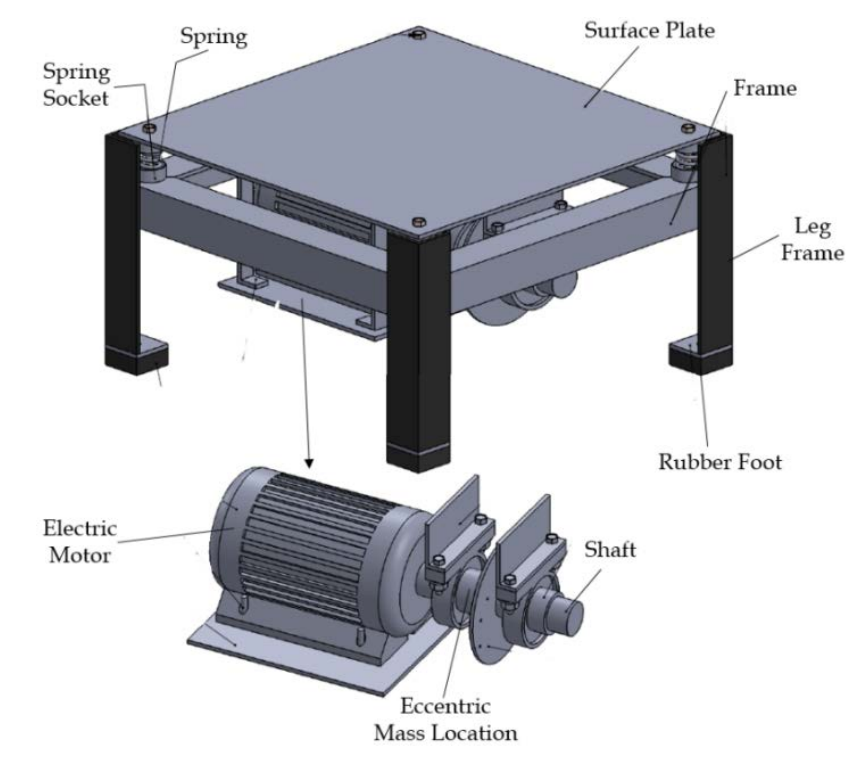

Fig. 1: Vibration Exciter

\subsection{Design Description and Calculations for Essential Machine Components}

The essential components of the 7-degree of freedom vibration exciter are briefly described in this section. Design calculations for these components are also presented. The calculations are based on the models presented in standard design reference and data texts [Khurmi and Gupta, 2005, Hall et al., 1982, Bhandari, 2014].

\subsubsection{Electric Motor}

The vibration exciter is to be used for laboratory applications, therefore the electric motor required should be of average size and capacity ratings. Hence, an electric motor of rated power (P) of $750 \mathrm{~W}$ and speed (N) of $1400 \mathrm{rpm}$ was selected. This will transmit a torque (T) of $5.1 \mathrm{Nm}$ based on Eq. (1).

$$
T=\frac{60 \times P}{2 \pi N}
$$

\subsubsection{Shaft}

Power is transmitted to the eccentric mass, which generates vibration on the vibration exciter, through a shaft on which the mass is mounted. The shaft transmits motion and torque from the electric motor to the vibration exciter. Therefore, it is essential to design for the adequate size of the shaft which can withstand the twisting and bending moments it is subjected to. The length of the shaft was chosen as $200 \mathrm{~mm}$ to minimize bending moment and deflection. The shaft configuration is presented in Fig. 2, where points A and B represent the positions of the bearings on the shaft while point $\mathrm{C}$ is the eccentric mass location. 
The dynamic eccentric force on the shaft $\left(\mathrm{F}_{\mathrm{C}}\right)$ can be expressed as

$$
F_{C}=m e \omega^{2}
$$

where $\mathrm{m}$ and e are the mass and radius of the eccentric mass and $\omega=\frac{2 \pi \mathrm{N}}{60}$ is the angular velocity of the shaft. In this work, the considered mass and radius of the eccentric mass are limited to maximum of $30 \mathrm{~g}$ and $60 \mathrm{~mm}$ respectively. Hence, the force at point $\mathrm{C}$ is computed as $\mathrm{F}_{\mathrm{C}}=38.68 \mathrm{~N}$. Through force analysis, the forces at the two bearing locations $\mathrm{F}_{\mathrm{A}}=\mathrm{F}_{\mathrm{B}}=$ 19.34 N. Through bending analysis, bending moment at the bearing locations are zero. At point $\mathrm{C}, \mathrm{M}_{\mathrm{C}}=0.967 \mathrm{Nm}$. From Fig. 2, the maximum bending moment is obtained as $\mathrm{M}=0.967 \mathrm{Nm}$.

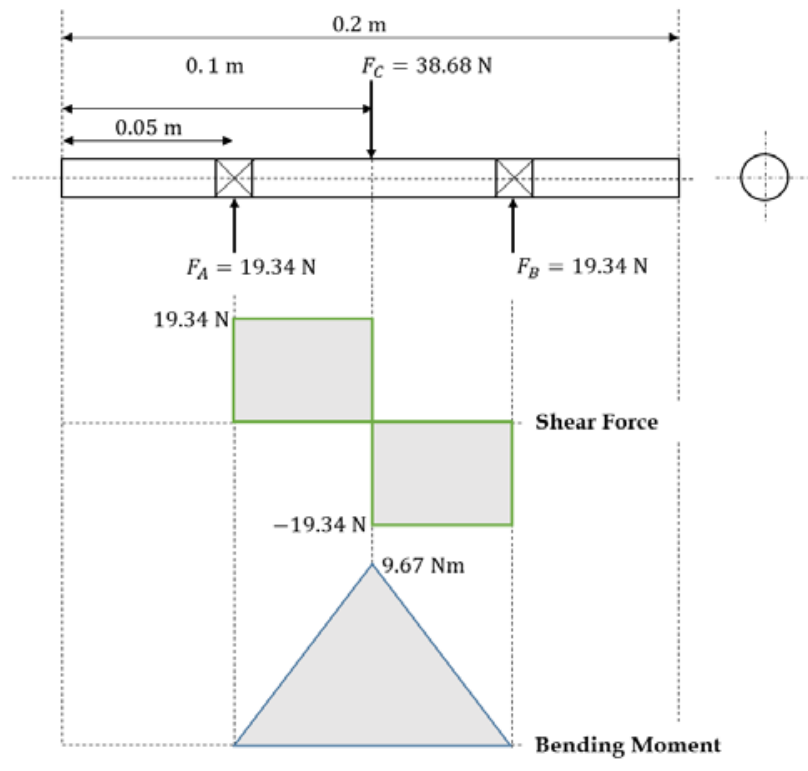

Fig. 2: The Shaft Configuration and its Shear Force and Bending Moment Analyses

The suitable shaft diameter is then determined using the calculated torque and bending moment as

$$
d^{3}=\frac{16}{\pi \tau} \sqrt{M^{2}+T^{2}}
$$

where $\tau$ is the permissible shear stress. Considering an adequate factor of safety, $\tau$ is taken as $0.4725 \mathrm{MPa}$ for a steel shaft. The shaft diameter is then calculated as $38.3 \mathrm{~mm}$. The diameter is taken as $40 \mathrm{~mm}$.

\subsubsection{Bearing}

The radial ball bearing is selected for this device due to its known advantages such as low friction as well as ease of maintenance and replacement. Bearing 6308, of inner diameter of $40 \mathrm{~mm}$, outer diameter of $90 \mathrm{~mm}$ and a width of 23 $\mathrm{mm}$, was chosen. The rating life $\mathrm{L}$ of the bearing is estimated as

$$
L=\left(\frac{C}{W}\right)^{3} \times 10^{6}
$$

where $\mathrm{C}$ and $\mathrm{W}$ are respectively the basic and the equivalent dynamic load ratings of the bearing.

\subsubsection{Spring}

Helical spring with squared and ground ends made of carbon steel material was selected for the device for a good stability. As shown in Fig. 1, the springs are introduced between the frames and eccentric assembly of the machine to help isolate the vibratory forces from the machine supports. Mechanical tests were conducted to determine the spring stiffness and weight. The experimental set up for the experiment is as shown in Fig. 3. 


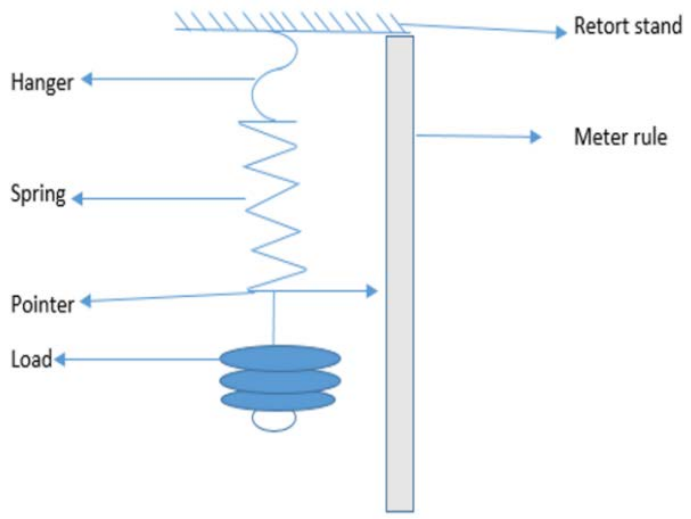

Fig. 3: The Experimental Set-Up for Determining the Stiffness of the spring.

As shown in Fig. 3, a known mass was loaded on the hanger and the new position of the pointer was recorded. This was repeated for a number of masses and a plot of mass against displacement was recorded. The stiffness of the spring was obtained as $4479 \mathrm{~N} / \mathrm{m}$ and the weight of the spring as $0.13 \mathrm{~kg}$. Other essential properties of the spring include mean $D$ and wire $d$ diameters of $25 \mathrm{~mm}$ and $4 \mathrm{~mm}, 50 \mathrm{~mm}$ free length and $8 \mathrm{~mm}$ pitch. It is essential to determine the maximum shear stress of the spring for fatigue design. This is obtained as

$$
\tau_{\max }=k_{w} \frac{8 F C}{\pi d^{2}}
$$

where $F$ is the weight acting on the spring, which is computed as the sum of the eccentric assembly and the table top weights as $307.84 \mathrm{~N}$. The spring index $C$ is obtained as

$$
C=\frac{D}{d}
$$

and the Wahl stress factor $k_{w}$ as

$$
k_{w}=\frac{4 C-1}{4 C-4}+\frac{0.615}{C}
$$

Hence, the maximum shear stress is calculated as $33.07 \mathrm{MPa}$. This is significantly lower than the allowable maximum shear stress of $42 M P a$, so the design is within a good limit.

\subsubsection{Numerical Modelling of the Kinematics of the Equipment}

A numerical model of the seven degrees of freedom motion of the designed system was developed by applying physical laws. The physical model of the system is represented in Fig. 4. The system has two different types of masses, namely sprung mass and unsprung mass. The sprung mass is the portion of the equipment supported by the springs which include the table surface and its attachments (i.e. the eccentric assembly). The unsprung mass is mainly contributed by the four springs. Overall, these masses constitute seven degrees of freedom in the system.

The vertical displacements of the unsprung masses are represented as $x_{21}, x_{22}, x_{23}$ and $x_{24}$. By applying D’Alembert principle, assuming uniform spring stiffness, the equations of motion at the corners can be expressed as

$$
\begin{aligned}
& m \ddot{x_{21}}+k x_{21}=0 \\
& m \ddot{x}_{22}+k x_{22}=0 \\
& m x_{23}^{\ddot{2}}+k x_{23}=0 \\
& m x_{24}+k x_{24}=0
\end{aligned}
$$

where $m$ is the unsprung mass of the springs and $k$ the spring stiffness. The sprung mass has three vibration modes, namely pitch, roll and vertical. The pitch mode $\theta$ rotates around a transverse axis (angular displacement), the roll mode $\varphi$ rotates around a longitudinal axis (angular displacement) and the vertical mode $x$ twists and oscillates about a vertical axis (vertical displacement). The equation of motion for the vertical, pitch and roll vibration modes of the table surface are respectively obtained as 


$$
\begin{gathered}
m_{s} \ddot{x}-k x_{21}-k x_{22}-k x_{23}-k x_{24}=0 \\
I_{\theta} \ddot{\theta}+\left(k x_{21}+k x_{24}\right) a-\left(k x_{22}+k x_{23}\right) b=0 \\
I_{\varphi} \ddot{\varphi}+\left(k x_{23}+k x_{24}\right) c-\left(k x_{21}+k x_{22}\right) d=0
\end{gathered}
$$

where $m_{s}$ and $I$ are the mass and the mass moment of inertia of the sprung masses. $a, b, c$ and $d$ are as shown in Fig. 4 .

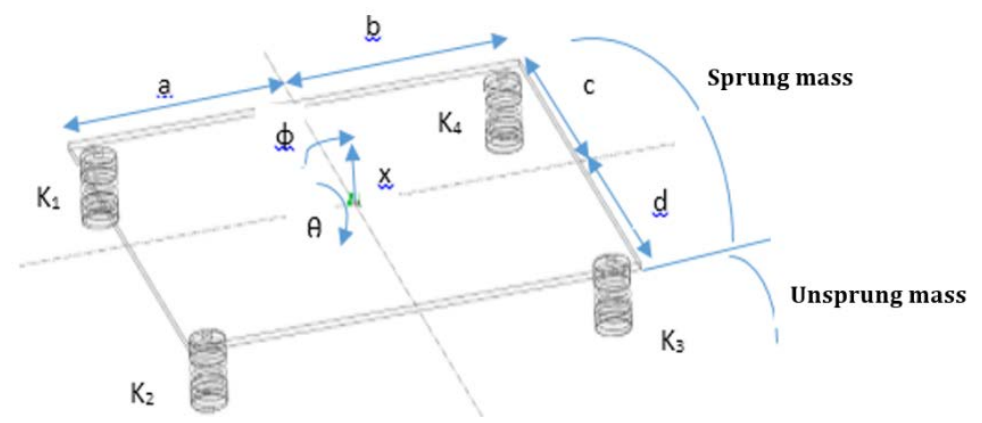

Fig. 4: The Physical Model of the Vibration Exciter.

\section{Fabrication of the Vibration Exciter}

The components of the device were machined and assembled with proper tolerance, dimensioning and specification with respect to the design analysis and drawings. Material selection was based the design parameters, material availability and cost in that order. Specifications of the main components of the device are summarized in Table 1.

Table 1: Part Lists and Specifications of the Device Components

\begin{tabular}{llll}
\hline Component & Material & Specification & Quantity \\
\hline Surface & Mild & $480 \mathrm{~mm} \times 480 \mathrm{~mm} \times 5$ & 1 \\
Table & Steel & $\mathrm{mm}$ & \\
Lower Table & Mild & $200 \mathrm{~mm} \times 200 \mathrm{~mm} \times 5$ & 1 \\
& Steel & $\mathrm{mm}$ & \\
Frame & Mild & $50 \mathrm{~mm} \times 50 \mathrm{~mm} \times 450$ & 4 \\
& Steel & $\mathrm{mm}$ & \\
Shaft & Mild & $\emptyset 40 \mathrm{~mm} \times 200 \mathrm{~mm}$ & 1 \\
Sompression & Steel & $\emptyset 30 \mathrm{~mm} \times 70 \mathrm{~mm}$ & 4 \\
Spring & Mild & $\emptyset 150 \mathrm{~mm}$ & \\
Disc Plate & Steel & & 1 \\
Eccentric & Mild & & 3 \\
Mass & Steel & & \\
Bearing & Steel & $\emptyset 40 \mathrm{~mm}$ & 2 \\
Electric & & $1 \mathrm{HP}$ & 1 \\
Motor & & $50 \mathrm{~mm} \times 50 \mathrm{~mm} \times 5$ & 4 \\
Rubber Foot & Rubber & $\mathrm{mm}$ & \\
\hline
\end{tabular}

The fabrication procedures of the main components are outlined as follows:

a) Frame

The frame is made from angle iron. It was introduced to withstand the dynamic load reactions of the system without causing deflections. The frames were cut from a blank bar into the required sizes using a cutting disc and were joined as required by welding using E115 mild steel electrode.

\section{b) Shaft and Coupling}

The shaft was machined on the lathe machine by turning a solid cylindrical blank into the required shaft diameter and length. The shaft was then coupled to the electric motor by centre boring one end of the shaft 19 mm diameter 40 
$\mathrm{mm}$ deep. This is equivalent to the diameter of the electric motor shaft. The motor shaft was then inserted into this shaft and both were bolted together for firmness and to avoid misalignment when in operation. This shaft transmits angular rotation and torque from the electric motor to the vibration exciter with the aid of the bearings attached on it.

\section{c) Disc and Eccentric Mass}

The disc plate was machined into the required size through marking-out and cutting operations. A $40 \mathrm{~mm}$ diameter hole was made at the centre of the disc for attaching it to the shaft. Also, three holes of diameter $6 \mathrm{~mm}$ at angle $45^{\circ}$ to one another were drilled, at points $30 \mathrm{~mm}, 50 \mathrm{~mm}$ and $65 \mathrm{~mm}$ from the edge of the disc, for attaching the eccentric loads.

\section{d) Surface Plate, Lower Plate and Bracelet}

The surface plate and the lower plate were machined into the required sizes from a blank. The lower plate is acting as a support for the electric motor. The two plates were connected together rigidly by 4 bracelets of $190 \mathrm{~mm}$ long. The bracelets were welded to the upper plate, while they were bolted to the lower plate. This is to allow for easy maintenance of the device.

\subsection{Brief Description and Operation of the Vibration Exciter}

The device is designed to generate vibratory motion using eccentric masses. Under the influence of the external excitation, the system masses move and set up inertia force. The main rotating shaft of the device is set into unbalance dynamically thereby inducing the cyclic or regular vibratory motion to the system.

A circular disc is fixed to the shaft coming from the electric motor. Eccentric loads are attached to the disc in such a way that it could be detached and attached easily as shown in the design. The distance from the centre at which the mass is placed to the shaft can also be varied and adjusted. This made it possible for the parameters of the vibration to be varied even at a constant speed of motor.

The arrangement is attached to a surface plate hanging beneath from the table surface while the table surface is supported on flexible elements (i.e. springs) at the four corners of the frame. This induces an oscillatory motion to the surface table. The force required to set up the vibratory motion is therefore generated by the electric motor and eccentric load, so minimal or no force is lost or transmitted to the surrounding structures (frames).

The transmission is direct from the electric motor via the shaft to the table surface through the bearings. These therefore eliminate the use of meshing gears, and so help to reduce noise and provide simplicity in the design and operation of the equipment.

\section{Results and Analysis}

Testing was performed on the developed vibration exciter in order to evaluate its performance and functionality. Initial test produced a satisfactory performance.

\subsection{Acceleration and Natural Frequency Measurements}

Accelerations of the vibration exciter, for vibrations along different directions, were measured using an accelerometer and oscilloscope set-up. The set-up displays the acceleration waveform with respect to time. The speed of the electric motor was monitored with a DT $-2235 \mathrm{~B}+$ Contact Surface Digital Tachometer. Results obtained from the oscilloscope were post-processed in MATLAB. The accelerometer has a sensitivity of 2048/count with a 16-bit resolution. Measurements were taken after running the equipment for about ten minutes in order to ensure a steady-state measurement.

The accelerations of the equipment vibration along the principal $\mathrm{x}, \mathrm{y}$ and $\mathrm{z}$ axes are presented in Fig. 5. Random sinusoidal signals are obtained in all the results. A maximum acceleration of $8 \mathrm{~m} / \mathrm{s}^{2}$ is obtained along the z-direction compared to maxima of $3 \mathrm{~m} / \mathrm{s}^{2}$ and $4 \mathrm{~m} / \mathrm{s}^{2}$ obtained along the $\mathrm{x}$ and $\mathrm{y}$ directions respectively. Highest acceleration range of $10 \mathrm{~m} / \mathrm{s}^{2}$ is also obtained along the z-direction compared to $7 \mathrm{~m} / \mathrm{s}^{2}$ and $9 \mathrm{~m} / \mathrm{s}^{2}$ obtained along the $\mathrm{x}$ and $\mathrm{y}$ directions.

The vibration angular accelerations of the equipment about the pitch $\theta$ and roll $\varphi$ directions are presented in Fig. 6 . Random sinusoidal signals are also obtained. A maximum angular acceleration of $40 \mathrm{rad} / \mathrm{s}$ is obtained for vibration about the pitch axis compared to $20 \mathrm{rad} / \mathrm{s}$ obtained about the roll axis. Also, the pitch axis has a higher angular acceleration range of $80 \mathrm{rad} / \mathrm{s}$ as against $60 \mathrm{rad} / \mathrm{s}$ about the roll axis.

Natural frequencies are calculated using the model equations developed in Section 2.2. The natural frequencies at the four spring's locations are obtained by solving Eq. (8) dynamically. Similarly, solving Eq. (9) gives the natural frequencies of the surface along the vertical, pitch and roll directions respectively. To solve Eq. (8), the mass and 
stiffness of each spring are required. As presented in Section 2.1.4, the spring mass and stiffness were obtained as 4479 $\mathrm{N} / \mathrm{m}$ and $0.13 \mathrm{~kg}$ respectively. Substituting these into Eq. (8) gives Eq. (10)

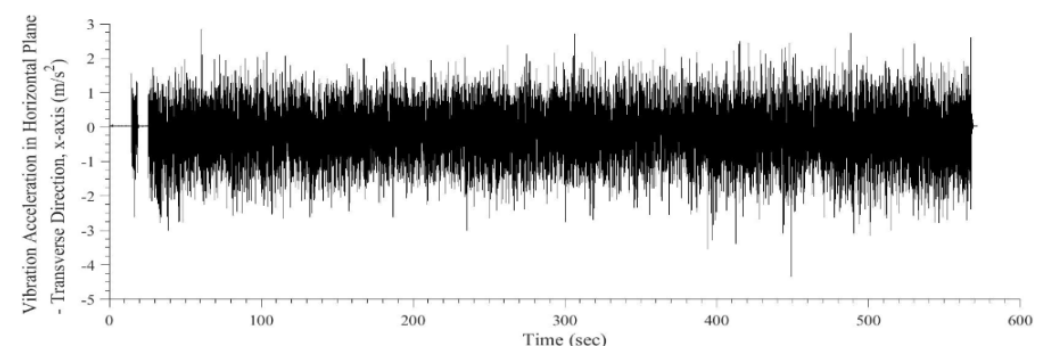

(a) $x$-axis

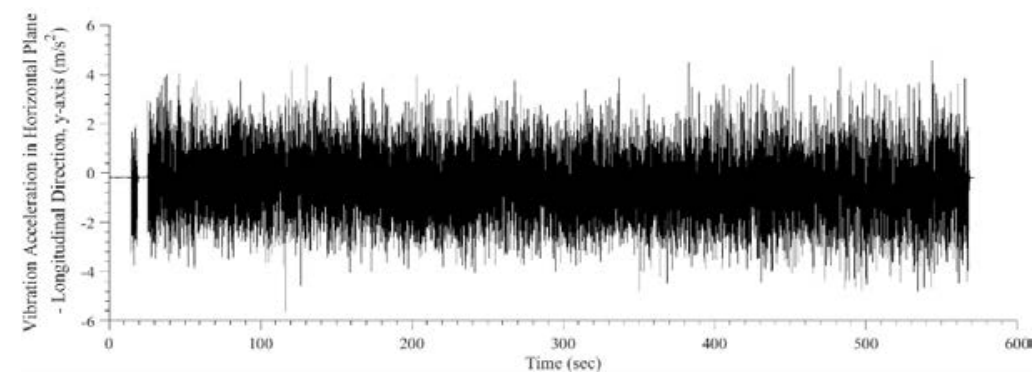

(b) $x$-axis

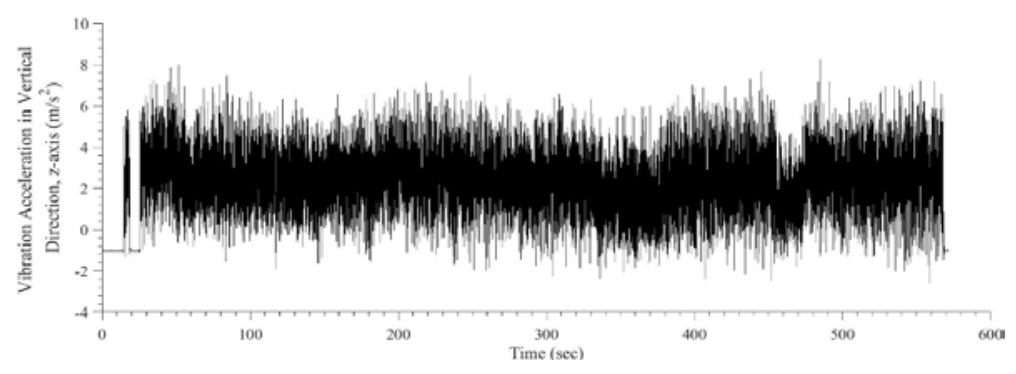

(c) $x$-axis

Fig. 5: Vibration Accelerations along the Principal Axes

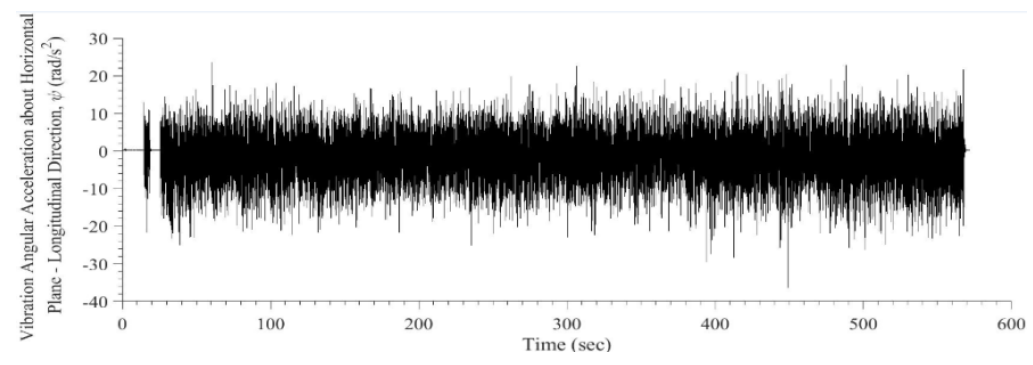

(a) $\theta$-axis

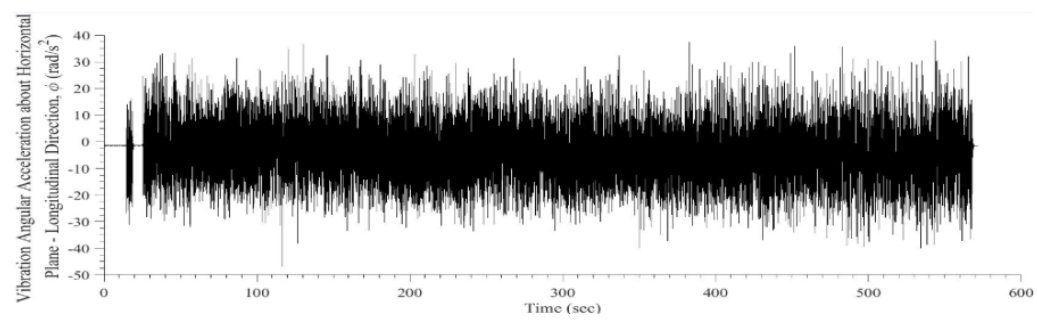

(b) $\varphi$-axis

Fig. 6: Vibration Angular Accelerations about the Pitch $\theta$ and Roll $\varphi$ Directions 


$$
\begin{array}{ll}
0.13 \ddot{x_{21}}+4479 x_{21}=0 ; & 0.13 \ddot{x_{22}}+4479 x_{22}=0 ; \\
0.13 \ddot{x_{23}}+4479 x_{23}=0 ; & \text { and } \quad 0.13 \ddot{x_{24}}+4479 x_{24}=0
\end{array}
$$

Solving these equations gives a similar natural frequencies at the four locations of the springs as $29.5 \mathrm{~Hz}$. To solve Eq. (9), the total sprung mass $m_{s}$ of the equipment, which is constitutes of the eccentric assembly, the machine top surface and the eccentric masses, is obtained as $31.83 \mathrm{~kg}$. The mass moment of inertia of pitch $I_{\theta}$ and roll $I_{\varphi}$ vibration modes are obtained by summing the moment of inertia of the main component parts. These are obtained as $I_{\theta}=$ $0.863 \mathrm{kgm}^{2}$ and $I_{\varphi}=0.556 \mathrm{kgm}^{2}$. Substituting these and other parameters into Eq. (9) gives

$$
\begin{gathered}
31.83 \ddot{x}-4497 x_{21}-4497-4497 x_{23}-4497 x_{24}=0 \\
0.863 \ddot{\theta}+1075 x_{21}+1075 x_{22}-1075 x_{23}-1075 x_{24}=0 \\
0.556 \ddot{\varphi}+1075 x_{24}+1075 x_{23}-1075 x_{22}-1075 x_{21}=0
\end{gathered}
$$

Solving these equations, the natural frequencies of the machine top surface along the vertical, pitch and roll directions are obtained as $f_{x}=3.78 \mathrm{~Hz}, f_{\theta}=7.94 \mathrm{~Hz}$ and $f_{\varphi}=9.89 \mathrm{~Hz}$ respectively. The presented results indicate that the developed machine has successfully satisfied the proposed hypothesis of being able to measure vibration characteristics along different degree of freedom.

\subsection{Stress Analysis}

Stress analysis was conducted on the vibration exciter top surface, which carries the vibration load. The surface is designed for stress rigidity. The analysis was carried out using the SolidWorks CAD software. It was assumed during analysis that no geometrical irregularities occur in the component parts of the device. For instance, the springs contact points are modelled as stationary pivot points to avoid stress raisers (usually caused by holes or gaps). The vibration load on the table surface was modelled by subjecting the surface to a distributed acceleration force. Acceleration forces of $200 \mathrm{~N}, 250 \mathrm{~N}, 300 \mathrm{~N}$ and $350 \mathrm{~N}$ were considered. The stress analysis results for these acceleration forces are presented in Fig. 7.

The factor of safety of the table surface, for an applied vibration load, is obtained as the ratio of maximum stress to working stress. It was observed that, at the point of maximum stress values, the top surface has minimum safety factors of 2.14, 2.51 and 2.68 when the surface is subjected to vibration loads of $250 \mathrm{~N}, 300 \mathrm{~N}$ and $350 \mathrm{~N}$ respectively.

\section{Concluding Remarks}

A vibration exciter plays an essential role in improving the physical and mechanical properties of parts produced from manufacturing operations like casting and welding. In this work, a vibration exciter, which has the capability of attaining seven degrees of freedom, was designed, fabricated and tested. Using eccentric mass, vibration was generated and induced on the surface plate of the device. The vibration parameters were able to be adjusted by changing the mass and/or the eccentricity distance, depending on the degree of vibration needed. The device performed satisfactorily as it was able to generate different vibration parameters. The main contribution of this work has therefore been the development of an eccentric mass exciter whose eccentric force is varied using the unbalanced mass and its eccentric distance, and which generates vibration characteristics along different degrees of freedom. The project can be extended by incorporating a speed regulation device with the electric motor for the purpose of varying the motor speed especially during the machine operation. This would further enhance the variation of the vibration parameters. 


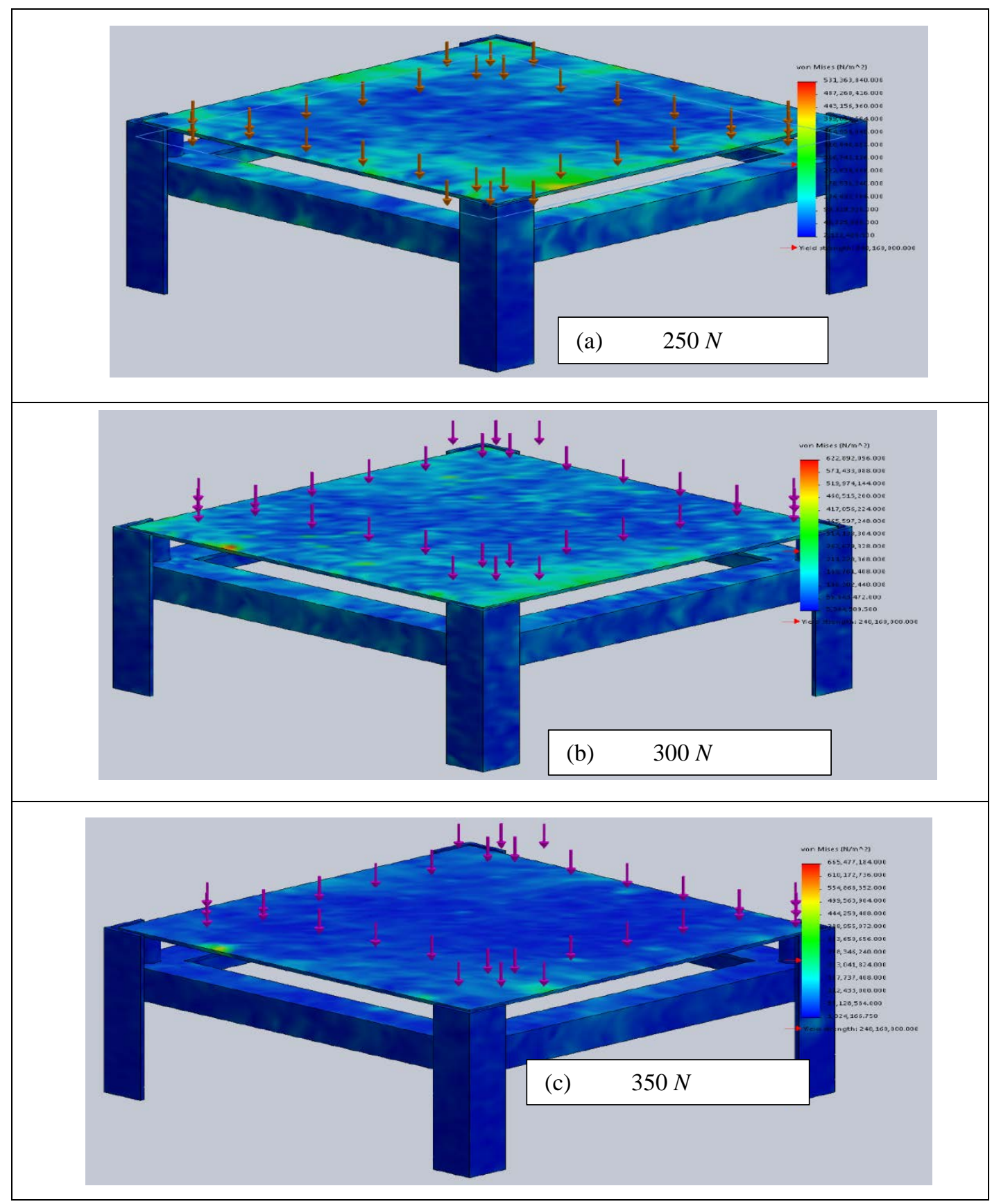

Fig. 7: Stress Analysis of the Vibration Exciter Top Surface at different Vibration Loads

\section{References}

[1] T. Tamura, M. Toshiro, M. Kenji, Effect of mechanical vibrations on microstructure refinement of Al-Si alloys, The Minerals, Metals and Material Society 11 (2011) 827-830.

[2] O. Dahunsi, A. Audu, The effects of vibration on the mechanical properties of low-carbon steel welded joints, NSE Technical Transaction 41 (2006) 61-72.

[3] F. Eshan, L. Dechao, K. Radovan, Application of vibration in the laser powder deposition process, Journal of Manufacturing Process 11 (2009) 38-44.

[4] A. Audu, O. Dahunsi, The effect of vibration on the impact strength and fracture resistance of welded point of low-carbon steel $(0.18 \% c)$, Spectrum Journal 10 (2003) 12.

[5] N. Omura, Y. Murakami, M. Li, T. Tamura, K. Miwa, H. Furukawa, M. Harada, M. Yokoi, Effects of mechanical vibration on macrostructure and mechanical properties of ac4c aluminium alloy castings, Materials Transactions 50 (2009) 2578-2583.

[6] Z. Zhao, Z. Fan, X. Dong, B. Tang, D. Pan, J. Li, Influence of mechanical vibration on the solidification of a lost foam cast 356 alloy, China Foundry 7 (2010) 24-29.

[7] R. Thoguluva, M. Sayuti, S. Sulaiman, Effects of mechanical vibrations on the properties, microstructure and fractography of titanium carbide particulate reinforced $\operatorname{lm} 6$ alloy composite castings, Indian Foundry Journal 58 (2012) 12. 
[8] A. Abugh, I. Kuncy, Microstructure and mechanical properties of vibrated castings and weldments: A review, Journal of Engineering Studies and Research 19 (2013) 7-12.

[9] Y. Zuo, X. Fu, Q. Zhu, L. Li, P. Wang, J. Cui, Effect of electromagnetic vibration on the microstructure of direct chill cast alzn-mg-cu alloy (2016).

[10] Y. Jianbo, R. Zhongming, E.Weile, D. Kang, Z. Yunbo, Effect of electromagnetic vibration on the structure and mechanical properties of al-si alloy during directional solidification, Acta Metallurgical Sinica 22 (2009) 35-39.

[11] R. Travieso, A. Jose, G. Gomez, J. Jorba-Peiro, D. Carrillo, A. Gilles, G. Joel, A. Hernan, Experimental study on the mechanical effects of the vibration-assisted ball-burnishing process, Materials and Manufacturing Processes 30 (2015) 1490-1497.

[12] P. Sakthivel, P. Sivakumar, Effect of vibration in tig and arc welding using aisi316 stainless steel, International Journal of Engineering Research and Science and Technology 3 (2014) 11.

[13] R. Apalowo, D. Chronopoulos, G. Tanner, Wave interaction with defects in pressurised composite structures, Journal of Nondestructive Evaluation 37 (2018) 48.

[14] A. Pawar, S. Vajre, S. Patil, A. Badade, K. Sasane, Design and fabrication of mechanical vibration exciter, International Journal of Mechanical Engineering and Technology 7 (2016) 58-75.

[15] V. Wowk, Machinery Vibration: Measurement and Analysis, Book-Mart Press Inc, USA, 1991.

[16] N. Anekar, V. Ruiwale, S. Nmbalkar, P. Rao, Design and testing of unbalanced mass mechanical vibration exciter, International Journal of Research in Engineering and Technology 3 (2014) 107-112.

[17] J. Gregory, Analysis of vibratory equipment using the finite element method, Unpublished Thesis, Graduate School, University of Wisconsin-Stout (2011) 222.

[18] M. Sayuti, S. Sulaiman, B. Baharudin, M. Arifin, T. Vijayaram, S. Sujara, Influence of mechanical vibration molding process on the tensile properties of tic reinforced $\operatorname{lm} 6$ alloy composite castings, Advances in Mechanical Engineering 2 (2012) 13-17.

[19] R. Khurmi, J. Gupta, A Textbook of Machine Design, Eurasia Publishing House, New Delhi, 2005.

[20] A. Hall, A. Holowenko, H. Laughlin, Theory and Problems of Machine Design, McGraw-Hill Book Co., Singapore, 1982.

[21] V. Bhandari, Machine Design Data Book, McGraw-Hill Education, 2014

\section{Authors' Profiles}

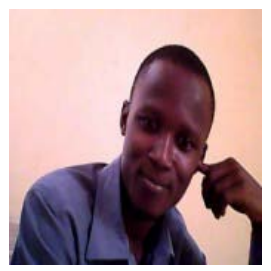

Oluwaseyi Isaac Oyedeji is a postgraduate student at the Department of Mechanical Engineering, Federal University of Technology, Akure Nigeria. He holds B.Eng. Degree in Mechanical Engineering from Ladoke Akintola University of Technology, Ogbomoso Nigeria and M.Eng. Degree in Mechanical Engineering from the Federal University of Technology, Akure Nigeria. He currently specialises on vibration and control of engineering structures.

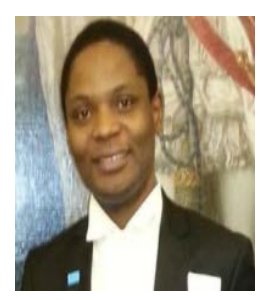

Rilwan Kayode Apalowo is a lecturer at the Department of Mechanical Engineering, Federal University of Technology, Akure Nigeria. He holds B.Eng. and M.Eng. Degrees in Mechanical Engineering from the Federal University of Technology, Akure Nigeria, and PhD (Mechanical Engineering) in Vibroacoustic of Aerospace Composite Structures from the University of Nottingham, United Kingdom. He currently specialises on the optimisation of dynamics of aerospace composite structures.

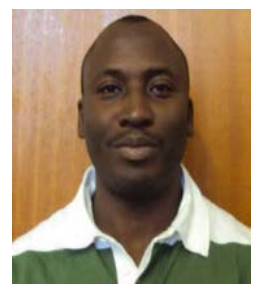

Olurotimi Akintunde Dahunsi is an associate professor at the Department of Mechanical Engineering, Federal University of Technology, Akure Nigeria. He obtained B.Eng. and M.Eng. Degrees in Mechanical Engineering from the Federal University of Technology, Akure Nigeria, and $\mathrm{PhD}$ in Mechanical Engineering from the University of Witwatersrand, Johannesburg, South Africa. He currently specialises on intelligent control and vibration mechanics.

How to cite this paper: Oyedeji O.I., Apalowo R.K.*, Dahunsi O.A., Audu A., " Development of a Multi Degree-of-Freedom Vibration Exciter for Laboratory Applications ", International Journal of Engineering and Manufacturing (IJEM), Vol.10, No.6, pp.110, 2020. DOI: 10.5815/ijem.2020.06.01 